\title{
O Projeto Ruas de Histórias Negras e a representação da matriz africana em Campinas: a disputa do território urbano - um estudo de caso
}

\author{
[ The Streets of Black Histories Project and a representation of the African \\ matrix in Campinas: a dispute of the urban territory - a case study
}

\section{Alessandra Ribeiro Martins ${ }^{\mathrm{I}}$ Wilson Ribeiro dos Santos Junior ${ }^{2}$}

\begin{abstract}
Este artigo é baseado na tese de doutorado Matriz africana em Campinas: territórios, memória e representação, de Alessandra Ribeiro Martins, sob orientação do prof. dr. Wilson Ribeiro dos Santos Junior, do Programa de Pós-Graduação em Urbanismo da PUC-Campinas, em fevereiro de 20I7. A pesquisa contou com o suporte financeiro da Coordenação de Aperfeiçoamento de Pessoal de Nível Superior (Capes).
\end{abstract}

RESUMO $\cdot O$ artigo tem como objetivo apresentar um resumo do estudo de caso do Projeto Ruas de Histórias Negras, que buscou evidenciar, através do levantamento de alguns monumentos, praças e ruas que receberam nomes de personagens negros, a presença da matriz africana na cidade. Campinas, como a maioria das vilas consolidadas durante a colônia com grande número de escravizados, acabou por desenvolver estratégias para a manutenção da ordem contra revoltas e fugas de escravizados, que influenciaram e acarretaram um processo permanente de apagamento da percepção dessa presença da matriz africana no espaço urbano. Nos últimos anos tornou-se mais acirrado o processo de reterritorialização desse espaço com novas iniciativas, ações e a participação de coletivos ligados a essa matriz. • PALAVRAS-CHAVE - Matriz africana; território; representação; requalificação urbana; patrimônio histórico-cultural. A ABSTRACT - This article aims to present a summary of the case study of the Streets of Black Stories Project, which sought to indicate through the survey of some monuments, squares and streets named after black people the presence of the African matrix in the city. Campinas, like most of the villages consolidated during the colony with large numbers of enslaved people, eventually developed strategies for maintaining order against revolts and escapes of enslaved people, which influenced and led to a permanent process of erasing the perception of this presence of the African matrix in urban space. In recent years the process of reterritorialization of this space has become more fierce with new initiatives, actions and the participation of groups related to this matrix. - KEYWORDS - African matrix; territory; representation; urban renewal; historical-cultural patrimony.

Recebido em 2I de fevereiro de $20 \mathrm{I} 7$

Aprovado em 30 de novembro de 2017

MARTINS, Alessandra Ribeiro; SANTOS JUNIOR, Wilson Ribeiro dos. O Projeto Ruas de Histórias Negras e a representação da matriz africana em Campinas: a disputa do território urbano - um estudo de caso. Revista do Instituto de Estudos Brasileiros, Brasil, n. 68, p. 32-49, dez. 2017.

DOI: http://dx.doi.org/Io.II6o6/issn.23I6-90IX.voi68p32-49

I Pontifícia Universidade Católica de Campinas (PUC-Campinas, Campinas, SP, Brasil).

2 Pontifícia Universidade Católica de Campinas (PUC-Campinas, Campinas, SP, Brasil). 


\section{TERRITórIO dE MATRIZ AFRICANA EM CAMPINAS}

A cidade de Campinas (SP) é um espaço vivo da manifestação do povo de matriz africana, seja por meio de fragmentos urbanos, seja pelas formas de uso e de manutenção de suas raízes culturais latentes, mesmo quando aparentemente estas não são vistas pela maioria de sua população. As marcas estão lá imbricadas nas transformações urbanas e sociais, sendo necessário, para observar a ritualização dessa memória, manter diálogos com os mais velhos dessa matriz africana, que preservam nas lembranças e em suas ações cotidianas essa materialidade ofuscada no espaço físico como âncora na transformação de um tipo de representação nas cidades atuais.

Em um contexto no qual o passado é evocado, esse campo permeado pela lembrança dessa presença de origem africana na cidade foi demarcado em Campinas desde o início do ciclo do açúcar, nos princípios do século XVIII. Com a utilização da mão de obra escrava, a população se ampliou e se diversificou: em I797, na ainda denominada Vila de São Carlos, a população era de 2.I07 pessoas, sendo 700 africanos, 330 agricultores, 550 mulheres brancas, 400 mulatas livres, I4 tropeiros, 9 comerciantes, 4 padres e I2 mendigos 3 . Esse é um momento de transformação econômica e demográfica; nota-se relativa autonomização econômica e também um significativo crescimento populacional: só para comparação, "em I775 a Freguesia contava com 247 habitantes e em I797 sua população era de 2.107 pessoas, um crescimento de aproximadamente $753 \%$ "4.

Segundo Rodrigues5 , na década de I830, aproximadamente um terço da produção

3 BERGÓ, Maria Stela de Abreu. Estudo geográfico da cidade de Campinas. In: CONGRESSO BRASILEIRO DE GEOGRAFIA, Io, I944, Rio de Janeiro. Anais, v. 3. Rio de Janeiro: Conselho Nacional de Geografia, I952, p. 64I-694.

4 Ibidem.

5 RODRIGUES, Fabíola. Perfil populacional de Campinas: a contribuição das migrações. In: PESSOA, Ângelo E.

S. (Org. e Coord.). Conhecer Campinas numa perspectiva histórica. Campinas: Secretaria Municipal de Educação, 2004 . 
açucareira de São Paulo se devia a Campinas. Em razão de o plantio de açúcar ser sustentado pelo trabalho escravo, nesse mesmo período, a população escrava de Campinas representava $5 \%$ da população escrava total da província de São Paulo, o que fazia da cidade o maior mercado comprador e distribuidor de escravos da província. Foi nas primeiras décadas do século XIX que a população escrava de Campinas alcançou participação expressiva no total do contingente populacional da cidade: segundo os censos, em I774, a população escrava correspondia a I8,3\% do total da população, alcançando 33,8\% em I8I4 e 56,2\% em I829, quando chegou a representar quase $60 \%$ da população total. Apesar de, a partir dos anos I860, o ritmo de crescimento da população escrava ter diminuído em função da proibição do tráfego negreiro, em I874 Campinas alcançou um elevado número absoluto de população escrava: 9.986 pessoas.

A transição das relações de produção do complexo cafeeiro da fase escravista para a capitalista trouxe para Campinas um aumento significativo de estrangeiros, basicamente europeus, o que significou a substituição do trabalho escravo pelo livre e acarretou diversas mudanças na estrutura social.

Enquanto os estrangeiros chegavam à nova terra com a firme aspiração de conseguir seu "pedaço de chão", graças às políticas do período de acolhimento aos imigrantes, para os ex-escravos as possibilidades eram reduzidas. Aos que ficaram na cidade restaram os cortiços, as favelas em formação e demais formas de moradias periféricas.

A conquista de um pedaço de chão em Campinas e na maioria das cidades brasileiras não foi tarefa fácil, porque, além do custo, outro fator se impunha nessa busca: a diferenciação social.

É relevante perceber que a desigualdade espacial se incorporou à desigualdade social. No espaço urbano, fundamentam-se os interesses do capital, a ação do Estado e a luta dos seus ocupantes como forma de resistência contra a segregação e pelo direito à cidade, que é formada pelos seus diferentes bairros, cada um com estrutura própria, particularidades, histórias que reúnem diversidades em uma vida cotidiana coletiva com atividades que criam e moldam as dinâmicas do fenômeno urbano.

No entanto, são os registros dessa presença numericamente majoritária, embora apagada, que se fazem presentes do ponto de vista do patrimônio material e imaterial de matriz africana e, ao mesmo tempo, ensejam a busca por compreender como essa matriz influenciou e influencia o ambiente e a forma urbana de Campinas, mesmo tendo em vista que a participação da população negra no contingente populacional foi reduzida.

Quando os coletivos ligados à matriz africana se estruturam e reterritorializam ${ }^{6}$ suas ações, tendo a criatividade como elemento gerador, cresce o grau de liberdade. Nessa perspectiva as ruas, praças e logradouros de matriz africana consolidam e impactam a cultura local de Campinas.

Para as comunidades e povos de matriz africana, adotamos a definição da

6 Reterritorialização, nesta pesquisa, se aplica aos diversos aspectos do uso de um território, quando comunidades, grupos e coletivos se apropriam ou ocupam na busca de fortalecer sentidos, mesmo que no passado esse território não tenha sido "formalmente" deles. A reterritorialização perpassa aspectos econômicos, cartográficos, simbólico-culturais, de fronteiras políticas, etc. Cf. HAESBAERT, R. Territórios alternativos. Niterói: Eduff; São Paulo: Contexto, 2002. 
Secretaria Especial de Políticas de Promoção da Igualdade Racial - Seppir: povos, comunidades e coletivos que se identificam e se reconhecem, povos que resistem e preservam a cultura afrodescendente, caracterizando-se pela manutenção de um contínuo civilizatório no Brasil e constituindo territórios próprios marcados pela vivência comunitária, pelo acolhimento e pela prestação de serviços.

Para esta pesquisa, entretanto, entendemos a matriz africana também como toda herança ancestral, cultural, territorial, monumental, linguística e organizacional, encontrada tanto em documentos quanto em vestígios urbanos ou transmitidos oralmente pelos negros africanos escravizados e preservados no território pela memória através de manifestações, reinvenções e reterritorializações em Campinas, manifestando-se através das ações permanentes dos grupos, organização das marchas reivindicatórias, cortejos, manifestações culturais, práticas religiosas dos povos e comunidades tradicionais de terreiro.

Essas manifestações têm como representação fundamental para sua existência o compromisso com a transmissão de saberes, salvaguarda e preservação dessa ancestralidade africana, incluindo a luta permanente contra o racismo, discriminação e intolerâncias diversas.

A herança cultural de matriz africana, em seus saberes, valores e ritos, tem ganhado maior visibilidade por meio da luta do movimento negro, dos grupos culturais e das comunidades tradicionais de terreiro. Valorizar a riqueza dessa contribuição implicou na obrigação e na contradição de reconhecer o lugar de subalternização e estereotipia vinculado aos negros na sociedade brasileira e o compromisso com a transformação dessa realidade e de sua identidade territorial.

O artigo 68 da Constituição de 1988 reconhece, no ato das disposições constitucionais territoriais, o direito que as comunidades remanescentes de quilombos têm às terras que ocupam, assim como a obrigação do Estado de legalizar esse direito constitucional aos remanescentes quilombolas. A redação desse artigo deixa clara sua intenção de reparação histórica e valor simbólico, voltado ao restrito universo dos "remanescentes" daqueles que foram ícones da resistência à escravidão. Portanto, muitas vezes, não é possível recorrer a uma memória já estabelecida para justificar um território, mas, ao contrário, somente a partir do território é que se pode recuperar as memórias esquecidas ou invisibilidades no contexto urbano e as prioridades territoriais da cidade.

Thompson ${ }^{7}$ observou que as pessoas também lidam com suas experiências como sentimentos, tratados culturalmente como "valores", explicitados na relação com "normas, obrigações familiares e de parentesco ou, em suas formas mais elaboradas, nas convicções religiosas". Tanto quanto as necessidades materiais, os valores são "sempre um terreno de contradição, de luta entre valores e visões de vidas alternativas". Ou seja, considerar, conforme Thompson, que toda luta social é ao mesmo tempo uma luta acerca de valores permitiu perceber, de forma mais ampla, quanto esses territórios de matriz africana são possíveis de ser desvendados de modo a possibilitar uma nova releitura sobre essa mesma cidade.

7 THOMPSON, Edward Paul. A miséria da teoria. Rio de Janeiro: Jorge Zahar, I98I, p. 47-6I. 
Rolnik $^{8}$ afirma que o patrimônio simbólico do negro brasileiro nestas circunstâncias urbanas se firmou no Brasil como "território político-mítico-religioso", para sua transmissão e preservação. Um dos suportes mais sólidos aos escravizados, para a manutenção desta preservação e transmissão, "foi o pátio da senzala, símbolo de segregação e controle, que se transformou em terreiro como lugar de celebração das formas de ligação da comunidade". Na atualidade, o terreiro também é (re) existência e, por meio de um processo de requalificação urbana, a Fazenda Roseira do Campo Grande, atual Casa de Cultura Fazenda Roseira, em Campinas, tornou-se um outro espaço de observação: no passado, os escravizados ficavam restritos às senzalas e ao trabalho forçado; com o processo de ocupação e agora gestão formalizada pela comunidade jongueira Comunidade Jongo Dito Ribeiro, os seus descendentes hoje têm acesso às salas da casa grande como terreiro das manifestações culturais de matriz africana.

Fortalecer a manutenção das memórias, dos territórios e o desenvolvimento de políticas públicas que se apoiem na visibilidade e reconhecimento dessa contribuição da matriz africana em Campinas potencializa a construção da diversidade do país e ao mesmo tempo colabora com a valorização da cultura afrodescendente na busca de redimensionar as relações sociais e políticas em favor da igualdade e do respeito à diferença, tal como firmado pelo Estatuto da Igualdade Racial de julho de 2010.

\section{PATrimônio CUltural (MATERIAL E IMATERIAL): Símbolos URbanos}

[...] É a relação com o passado que torna um indivíduo membro de uma comunidade humana. Desta maneira grupos historicamente discriminados tendem a buscar as mais diversas formas de reparação; uma delas se dá no campo da história, em ter reconhecida a sua particularidade histórica dentro daquela comunidade e, assim, sentir-se inserida nela?.

A Igreja em Campinas, que atuou como braço do Estado e da manutenção da ordem social durante o período da colônia e império, elaborou diversas estratégias para que seus símbolos e representações fossem mantidos, criados e recriados como materialidade do poder.

São inúmeros os registros em Campinas da relação das igrejas com os homens de bem, assim como do Pelourinho e da Forca como espaços de castigo e exemplo de repreensão para os que tinham “má conduta”, e da constituição de irmandades ligadas aos pretos e às igrejas como busca de caminhos para a conquista da liberdade e alguns apoios aos escravizados, livres e libertos.

Em todas essas representações, a rua, a cidade, as praças, os monumentos, os edifícios e diversos espaços públicos tiveram, e ainda têm, importante papel na

8 ROLNIK, Raquel. A cidade e a lei: legislação, política urbana e territórios na cidade de São Paulo. São Paulo:

Fapesp/Studio Nobel, I977, p. 78.

9 HOBSBAWN, Eric. Sobre história. São Paulo: Companhia das Letras, I998. 
disputa de identidades nesse palco urbano representativo que lhes garante uma permanência que atravessa o tempo. $\mathrm{O}$ direito à memória, à cidadania e à própria cidade se efetiva pela tomada das ruas para reivindicações, protestos, marchas, festas ou comemorações, como a própria simbologia ao nomear esses lugares.

Ao ampliar esse olhar para a discussão do patrimônio cultural material ou imaterial, é importante ressaltar que o que é escolhido para ser preservado é parte de um projeto sobre identidade e memória coletiva e é mantido ao mesmo tempo que evidencia uma conjuntura política. O termo "conjuntura", no caso do Projeto Ruas de Histórias Negras, está diretamente ligado à Câmara dos Vereadores de Campinas e às sucessivas legislaturas como espaço de poder onde são efetivadas e aprovadas, ou não, as propostas de nomenclatura de ruas, praças e monumentos na cidade. Antigamente eram as Câmaras das Vilas que elaboravam e aprovavam essas leis, e os Códigos de Postura que estabeleciam os rigores e a forma de boa conduta e ordem social.

Atenta-se ao fato de que o historiador Américo Villela ${ }^{\text {Io }}$ aponta que, durante o período republicano, as ruas e avenidas da região central foram gradativamente rebatizadas, construindo uma nova representação em um processo no qual a reescrita da história e memória perpassou pelo apagamento de várias referências, lugares e presenças indesejadas. Essas mudanças ocorreram durante um forte impacto de urbanização devido ao crescimento da cidade nos anos 1900. Foram registrados cerca de 33.000 habitantes em 1872, e a modernidade, demarcada pela Revolução Industrial, acarretou a busca por novas referências e o apagamento das marcas da colônia escravocrata para a afirmação de uma república abolicionista.

Até o ano de I864, a nomenclatura de praças e ruas na Princesa do Oeste tinha um cunho popular. Quando não uma devoção religiosa, era o pitoresco que predominava nas placas das vias públicas, que acabavam sendo oficializadas pela Municipalidade. Cada templo católico, como a Matriz Velha, a Matriz Nova e a Igreja do Rosário, patrocinava uma rua. Por vezes, adotavam-se nomes de santos, como São Carlos, São José, São Pedro e o Bom Jesus. Campinas deve ao Dr. Ricardo Gumbleton Daunt o uso das legendas de homenagem cívica ou patriótica nas placas de ruas. E afirmamos, desde logo, que data de pouco mais de um século a apresentação à Câmara da primeira proposição cultuando nas vias públicas a memória dos antepassados ilustres ${ }^{\mathrm{II}}$.

A rua é um espaço revelador e um interessante palco de observação dos acontecimentos cotidianos. Através do seu constante movimento, é na rua que a vida social e as diversas formas de apropriação da cidade se revelam.

Como apresentou Mariano ${ }^{\mathrm{I2}}$, nomear ruas era uma relação com a vida cotidiana e com as experiências ali vividas. Existiram nomes como Rua Direita, Rua de Cima, Rua de Baixo, Rua do Chafariz, entre outros nomes comuns que possibilitavam

Io VILELLA, Américo Baptista. Representações da cidade: patrimônio cultural imaterial e memória republicana em Campinas. Revista CPC, São Paulo, n. 6, p. IO2-II8, maio-out.2008. Disponível em: <periodicos.usp.br/cpc/ article/view/I5626/I7200>. Acesso em: 23 nov. 2017.

II MARIANO, Julio. Campinas de ontem e anteontem. Campinas: Maranata, I970, p. II5.

I2 Ibidem. 
a localização por parte dos moradores locais e proporcionavam, através do reconhecimento simbólico pelo nome de compreensão comum, o fortalecimento de identidades e seu cotidiano vivenciado.

Segundo Goulart ${ }^{13}$, as placas de legendas de ruas da cidade nos primeiros tempos eram pintadas a pincel, o que garantia uma renovação constante por parte da Câmara. Só em I877, Bernardo Levy, um dos vereadores da província, propôs executar o emplacamento em chapas de ferro; por falta de recursos a Câmara recusou a proposta, que foi executada anos depois, em virtude da Lei n. 25 de I893, em placas de ferro ou bronze.

$\mathrm{O}$ ato de emplacamento estava associado, primeiramente, a uma necessidade e vontade política. Já desde essa época, o foco do desenvolvimento local estava bem mais voltado aos moradores da província e aos deslocamentos das caravanas que passavam rumo a Minas Gerais, Goiás e Cuiabá.

Recuperar a cidade do passado implica de uma certa forma em não apenas recuperar lembranças, relatar fatos, celebrar personagens, reconstruir, reabilitar ou restaurar prédios, preservar materialmente espaços significativos do contexto urbano. Todo traço do passado pode ser datado através do conhecimento científico ou classificado segundo um estilo preciso, mas o resgate do passado implica em ir além dessa instância, para os domínios do simbólico e do sensível, ao encontro da carga de significados que esta cidade abrigou em um outro tempo. Ao salvaguardar a cidade do passado, importa, sobretudo, fixar imagens e discursos que possam conferir uma certa identidade urbana, um conjunto de sentidos e de formas de reconhecimento que a individualizem na história ${ }^{\mathrm{I} 4}$.

Olhar a cidade sem a preocupação efetiva com nomes de ruas começa a mudar quando se acirram as disputas entre quais memórias seriam interessantes para serem guardadas e preservadas na cidade. Ao relacionar essas denominações iniciais das ruas com a recuperação de lembranças e percepções de algumas práticas culturais de matriz africana, há personalidades negras que também foram oficializadas entre essas memórias e que permanecem até hoje. Por exemplo, a Rua I3 de Maio, que indica e registra a abolição da escravatura.

[...] para comemorar a gloriosa data daí redentora, que encheu de júbilo a população da cidade e seu Município, o vereador republicano Dr. Salvador Leite de Camargo Penteado propôs na sessão ordinária de 28 daquele mês e ano a mudança do nome da "Rua São José" para Rua I3 de Maio, que foi aprovada com voto contrário do edil Dr. Ricardo G. Daunt, que assim se justificou: "Tal mudança simbolizando a vitória de um partido sobre o outro importa grave ofensa aos aderentes de causa vencida, e contando-se entre estes além de outros muitos cidadãos, a máxima parte de indivíduos pertencentes às famílias territoriais, cuja influência social é por necessidade grande e a quem o

I3 GOULART, Edmo. Campinas: ruas da época imperial. Campinas: Maranata, I983, p. I9.

I4 PESAVENTO, Sandra Jatahy. Cidade, espaço e tempo: reflexões sobre a memória e o patrimônio urbano.

Cadernos do Lepaarq, v. 2, n. 4, ago.-dez. 2005, p. II. 
Município deve em máxima parte seu estado de prosperidade, e as instituições de que legitimamente se orgulha [...]”. Essa justificativa foi combatida pelo camarista José de França Camargo, que não concordou com o seu conteúdo. A primitiva legenda "Rua São José”, oficializada em I848, adveio do acendrado sentimento religioso do povo [...]. Hoje a Rua I3 de Maio está transformada em elegante convívio, com variado e sempre crescente número de casas comerciais, porém, conservando aquela sua tradição no ramo de calçados ${ }^{\text {I5 }}$.

Ainda hoje, a Rua I3 de Maio acolhe festividades, movimentos sociais e ações dos povos e comunidades tradicionais de matriz africana, como uma ação permanente e não exclusiva. Contudo, mantém o caráter de fundo político-social, reivindicatório e festivo. A matriz africana ainda inclui a preservação da cosmovisão ancestral.

Sempre foi comum, desde a época da escravidão, evidenciar que o ato de ocupar ruas e praças e interagir com os espaços urbanos consistia em uma estratégia para a interação dos povos e comunidades de matriz africana para trocas culturais e de informação e articulação e para salvaguardar práticas antigas. Em São Paulo, por exemplo, havia o Beco das Minas, onde, durante a noite, vendedoras negras, forras e escravizadas praticavam a arte tradicional do comércio ambulante e das feiras de comestíveis e gêneros de primeira necessidade. Segundo Rolnik ${ }^{\mathrm{I}}$, além das escravizadas de tabuleiro, trocava-se também entre os escravizados bens de prestígio, como aguardente, fumo mágico ou religioso, ervas, velas, estatuetas de barro e frangos, estabelecendo relações que adquiriam um sentido para além do econômico, envolvendo relações também comunitárias, no caso, práticas essencialmente femininas. Essas relações permitiam a troca de informações e garantiam a sobrevivência nos quilombos urbanos, lugares onde se açoitavam os escravizados fugidos.

Art. I7 O artigo 76 do Código de Posturas fica alterado da maneira seguinte: todo escravo que for encontrado na rua depois das dez horas da noite, sem bilhete de seu senhor, será preso, e no dia seguinte entregue a quem pertencer.

[...]

Art. 31 O artigo 74 das Posturas fica substituído pelo seguinte: Ninguém poderá brincar entrudo nas ruas e praças da cidade, sob multa de cinco mil réis. Sendo proibido vender laranjinhas ou limões de cheiro, os quais sendo encontrados serão inutilizados e seus respectivos donos multados em dez mil réis ${ }^{\mathrm{I}}$.

Essa e outras posturas evidenciavam o quanto era fundamental a manutenção da ordem e ao mesmo tempo o controle sobre a vida, em especial, dos escravizados libertos e livres no espaço da rua.

I5 GOULART, Edmo, op. cit., I983, p. 8I-82.

I6 ROLNIK, Raquel, op. cit., p. 6I.

I7 PREFEITURA Municipal de Campinas. Câmara Municipal de Campinas. Arq-Camp. Base de dados de referências de acervos arquivísticos públicos de Campinas. Código de Posturas de I872. Disponível em: <arq-camp.campinas.sp.gov.br/index.php/pI7?symfony=3eqjsoIfv5d4Itcahv2tckdqr3〉. Acesso em: 23 nov. 2017. 
Todavia, após a abolição e a elaboração de novas leis no Brasil, o ato de ocupar a rua passou a ser permitido a toda a população, principalmente quando a rua se tornou espaço de lutas e reivindicações. Várias praças, largos e ruas em Campinas ganharam essa referência e visibilidade. De acordo com a demanda popular de luta, são os lugares a serem ocupados para mobilização.

A Praça Anita Garibaldi, com todo seu referencial de memória da presença negra em Campinas, tornou-se palco das ações comemorativas de datas simbólicas, como 20 de novembro, I3 de maio, entre outras manifestações recriadas ao longo do tempo, como também foi o pilar para o desenvolvimento de um dos importantes projetos da atualidade na cidade de Campinas: o Projeto Ruas de Histórias Negras.

\section{A disputa do território de matriz africana: PraÇa Anita GaRibaldi $X$ RUAS DE Histórias NegRas - ESTUdO dE CASO}

A história ensina que em cada recorte temporal a voz que será evidenciada perpassa por uma escolha. Com essa reflexão e tendo em mente o livro de Steve Biko, Eu escrevo o que eu quero ${ }^{18}$, para refletir sobre o Projeto Ruas de Histórias Negras se faz necessário um olhar mais ampliado para a presença do negro na política municipal e nas articulações junto ao poder público.

Em Campinas, a Câmara dos Vereadores, desde suas origens, foi o espaço que determinou e moldou os interesses estruturais da sociedade. Escolhas, posicionamentos políticos e interesses acabaram por produzir na cidade referências que foram legitimadas no decorrer do tempo, como fatos e memórias, conforme evidenciou Villela ${ }^{\text {19 }}$ na mudança do Império para República, quando várias ruas foram renomeadas para dar um sentido republicano e moderno à cidade.

No senso comum, desde que foi iniciada a percepção do território e dos lugares, sabe-se que as denominações de ruas, praças e placas registraram nomes de personalidades reconhecidas como "pessoas que foram importantes". Porém, nem sempre se busca entender quem deu nem a partir de qual perspectiva ou período histórico se deu essa importância. Entre outros elementos, esse nome representa e registra um momento comum, no qual a população como um todo esteve inserida.

Por isso se fez necessário investigar como a nomenclatura de ruas se dava para compreender os sentidos para que, por exemplo, defronte à Igreja São Benedito, a praça recebesse o nome de Anita Garibaldi.

I8 BIKO, Steve. Eu escrevo o que eu quero. São Paulo: Ática, I99o. Biko foi um importante líder da África do Sul durante o Apartheid, que consolidou o conceito de consciência negra para o mundo, criando forte impacto nas Américas e nas sociedades que sofreram e se formaram a partir da escravidão. Mesmo que estas apresentem outra realidade social e de estrutura, os conceitos e percepções por ele desenvolvidos se assemelham aos problemas e diferenças sociais concretizadas. Não havendo uma divisão por Apartheid e tendo a cor da pele como referência estruturante, nas práticas vivenciadas é percebido que o fator “pele”, quando esta é mais escura, ainda materializa profundas diferenças sociais, culturais, econômicas e de acesso à igualdade de direitos na sociedade contemporânea.

I9 VILELLA, Américo Baptista, op. cit. 
É inegável a importância da mulher, heroína e guerreira Anita Garibaldi para o Sul devido a sua participação na Guerra dos Farrapos ao lado do companheiro Giuseppe e sua contribuição dentro dos diálogos referentes ao feminismo.

Por outro lado, fortalecer, recriar e manter a memória da contribuição da matriz africana na cidade de Campinas é um compromisso da comunidade negra e dos grupos ligados a essa matriz. Rediscutir e/ou ressignificar a nomenclatura da praça se fez necessário e desencadeou um conjunto de ações, que resultaram no Projeto Ruas de Histórias Negras.

[...] A roda de jongo da Comunidade Jongo Dito Ribeiro é iniciada naquele 20 de novembro de 20I3, porém, o ato de perceberem que uma placa havia sido inserida no local acarretou diálogos antes do ato cultural, vasta conversa sobre como poderiam ter colocado naquele lugar que, para eles, era um espaço de resistência negra, o nome de Praça Anita Garibaldi. A dança, os tambores ritmados acompanhados dos pontos metafóricos, alguns sobre festejos e outros com críticas sociais, rememoravam os antigos terreiros das senzalas. Para quem assiste é um encanto curioso, mas certamente aos praticantes da comunidade é mais uma oportunidade de demarcar que aquele espaço da cidade, como todas as memórias ali associadas é um ato de resistência na busca pelo direito e participação na memória e identidade ${ }^{20}$.

A partir da roda de jongo do dia 20 de novembro de 20I3, as ações e diálogos foram iniciados e conduzidos por integrantes da comunidade jongueira, que entenderam que, se era possível inserir uma placa com breve biografia a respeito de Anita Garibaldi em uma praça que continha histórias, memórias, bibliografias referenciadas vinculadas à matriz africana e à presença da comunidade negra, deveria ser possível também inserir outras placas de mesmo conteúdo para ressaltar suas memórias e presença na cidade.

O fortalecimento das ações culturais em torno da cultura de matriz africana em Campinas, após a outorga do título de Patrimônio Cultural Imaterial do Brasil ao Jongo do Sudeste - Comunidade Jongo Dito Ribeiro, que foi a primeira a reunir na cultura do município a relação entre ancestralidade e cultura de matriz africana, despertou grande assédio de pesquisadores com interesse em compreender essa retomada de tradição.

A literatura de John Hope Franklin, no livro Raça e história, tem muito a oferecer a essa reflexão. Esse autor é um historiador de grande importância nos EUA, um dos fundadores dos estudos afro-americanos enquanto território de pesquisa e um

20 Registro das comemorações de 20 de novembro. Acervo da Comunidade Jongo Dito Ribeiro. O Jongo é um patrimônio imaterial, registrado como o Jongo do Sudeste pelo Instituto do Patrimônio Histórico e Artístico Nacional - Iphan, em 2005, que tem como elemento o toque, a dança e o canto metafórico. Essa prática cultural em Campinas é salvaguardada pela Comunidade Jongo Dito Ribeiro. Para saber mais sobre as ações e histórico dessa comunidade, ver: MARTINS, Alessandra Ribeiro. Requalificação urbana: a Fazenda Roseira e a comunidade Jongo Dito Ribeiro Campinas/SP. Dissertação (Mestrado em Urbanismo). Programa de Pós-Graduação em Urbanismo, Pontifícia Universidade Católica de Campinas, 20Ir. Disponível em: <tede. bibliotecadigital.puc-campinas.edu.br:8080/jspui/handle/tede/97> Acesso em: I5 fev. 2017. 
estudioso dos negros americanos. Como ele mesmo escreveu: Ao examinar a história de um povo, devemos distinguir entre o que verdadeiramente aconteceu e aquilo que os que escreveram a história disseram ter acontecido ${ }^{21}$.

Só se pode transformar o que se conhece, e a história da comunidade negra de matriz africana em Campinas ainda está sendo revelada, estudada e compartilhada para além das senzalas, dos castigos e do tronco.

O Projeto Ruas de Histórias Negras é parte dessa conquista. O que era uma intuição (e incômodo) ao ver a Praça Anita Garibaldi naquele lugar de referência propiciou um avanço importante, unindo conhecimento científico e articulação social e política. O projeto é uma realidade na cidade de Campinas: são 43 placas de biografias de personalidades negras espalhadas por vários cantos da cidade.

O que se deve fazer quando se manifesta qualquer incômodo coletivo é compreender suas origens e, para essa comunidade jongueira, tornou-se fundamental desenvolver uma estratégia para se apropriar dos caminhos para a inserção de placas urbanas.

$\mathrm{O}$ ato de dar nome a uma rua ou logradouro é tido por muita gente como algo menor, por vezes citado até em tom de crítica ou zombaria. Mas imagine morar em uma rua sem nome, não podendo receber uma carta, uma conta de luz e nem mesmo explicar corretamente a alguém onde mora porque, afinal de contas, a rua não tem nome e, muitas vezes, nem a casa tem número. Campinas é uma cidade em crescimento constante. Inúmeras novas ruas surgem anualmente e nomeá-las é obrigação da Câmara, por isso anualmente há um número significativo de projetos nesse sentido. "Nome de rua" pode parecer algo banal pra muita gente, mas, para quem morava em um lugar desprovido de nome e era privado de uma série de direitos por causa disso, é um ato importante ${ }^{22}$.

É responsabilidade de um vereador dar andamento ao processo de nomear ruas, praças, monumentos. Em diálogo entre a Comunidade Jongo Dito Ribeiro e a assessora Edna Lourenço, durante o primeiro mandato do vereador Carlão (Partido dos Trabalhadores - PT), aventou-se a possibilidade de reversão da placa que havia sido posta em espaço tão simbólico para a comunidade negra local. Ambas entenderam os limites e a impossibilidade dessa reversão.

Iniciando um novo processo, como seria possível realizar novas inserções de placas e/ou nomear novas ruas? Ou dar evidências às ruas, monumentos e praças que já possuíam personalidades ligadas a essa matriz africana?

Uma ampla pesquisa levantou os vários lugares de importância para a comunidade negra local, e a iniciativa ganhou impulso em 3 de dezembro de 20I4, quando a comunidade jongueira recebeu a visita da ex-ministra da Seppir, Matilde

2I FRANKLIN, John Hope. Raça e história - ensaios selecionados (I938-I988). Tradução de Mauro Gama. Rio de Janeiro: Rocco, I999.

22 Rafa Zimbaldi é vereador de Campinas e atual presidente da Câmara Municipal dos Vereadores. Ele evidencia nesse trecho de entrevista para a TV Câmara o quanto a ação de nomear ruas é de grande importância na atuação dos vereadores, como também, como no caso do Projeto Ruas Negras, pode evidenciar ação referente à inclusão social. Disponível em: <www.campinas.sp.leg.br/comunicacao/noticias/20I6/janeiro/nome-de-rua -uma-obrigacao-legal-20I3e-importante-20I3-dos-vereadores $>$. Acesso em: 30 nov. 2016. 
Ribeiro, em um lançamento de livro ${ }^{23}$ na Casa de Cultura Fazenda Roseira, atual sede da Comunidade Jongo Dito Ribeiro e contribuinte da ampliação dos debates, que passaram a ganhar mais fôlego na cidade.

Além da importante pesquisa sobre o movimento negro brasileiro e relações étnico-raciais que resultou nesse livro, a ex-ministra Matilde Ribeiro, em sua experiência como ministra na elaboração de políticas públicas para a igualdade racial, havia também realizado, após sua saída da Seppir, uma participação no Projeto sobre Ruas de Personalidades Negras na cidade de São Paulo e apontou sugestões para a assessora do vereador Carlão (PT), Edna Lourenço, sobre os possíveis caminhos políticos e trâmites para a execução dessa inserção na cidade de Campinas.

Em Campinas, já havia várias placas de personalidades históricas brancas que traziam uma breve biografia das personagens, mas não havia essas informações em ruas, monumentos e praças relacionadas às personalidades negras.

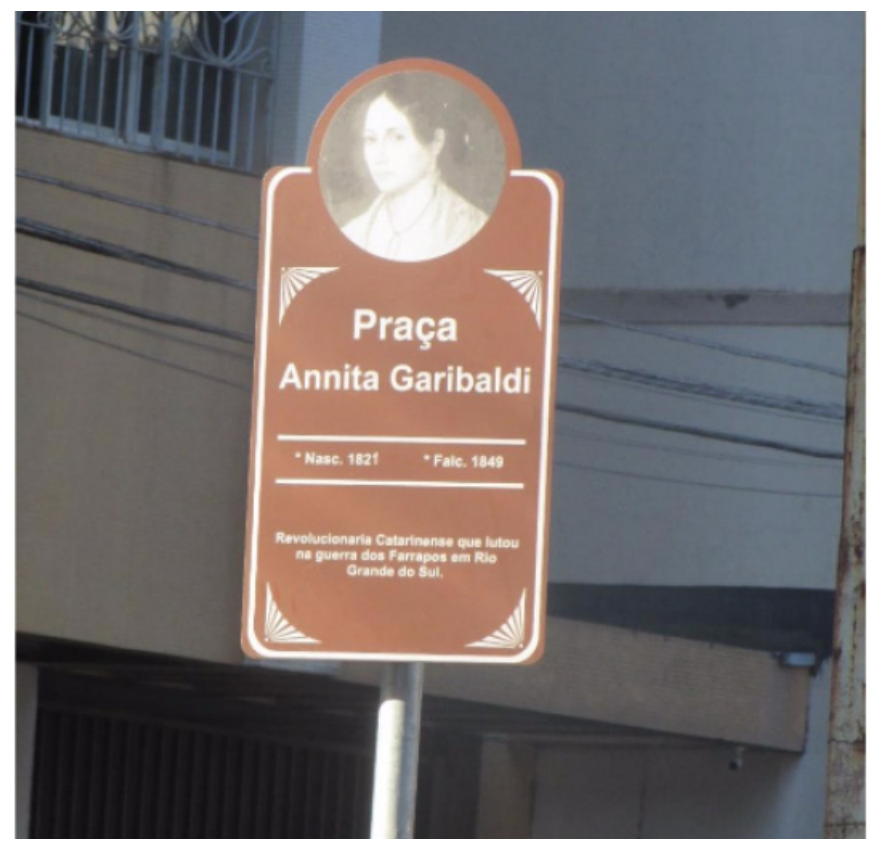

Figura I - Placa biográfica de Anita Garibaldi localizada na Praça Anita Garibaldi (em frente à Igreja São Benedito) ${ }^{24}$

Uma das importantes reflexões consolidadas nesse processo é que, no cenário

23 RIBEIRO, Matilde. Políticas de promoção da igualdade racial no Brasil - I986-20Io. Rio de Janeiro: Garamond, 2014 .

24 Fonte: MARTINS, Alessandra Ribeiro. Matriz africana em Campinas - territórios, memória e representação. Tese (Doutorado em Urbanismo). Programa de Pós-Graduação em Urbanismo, Pontifícia Universidade Católica de Campinas, 20I6, p. 72. Disponível em: <tede.bibliotecadigital.puc-campinas.edu.br:8080/jspui/ handle/tede/928>. Acesso em: 23 nov. 2017. 
político de Campinas, toda vez que a comunidade negra se mobiliza e consegue se apropriar e conhecer profundamente o desenvolvimento de determinada ferramenta e/ou quando a população, de modo geral, compreende o caminho e os processos formais de determinada política pública, a tendência é que esta se concretize. Nas questões sociais, raciais e religiosas na atualidade, envolvidas na política local, o compreender e o conhecer profundamente os caminhos de determinada demanda ou solicitação fortalecem as lutas e auxiliam para que essas ações se concretizem.

Mobilização, articulação e conhecimento transformam a sociedade e trazem conquistas importantes aos interessados. Esta pesquisa reitera que as questões da matriz africana e seus territórios têm que ser inseridas como parte dessa compreensão na dimensão do território político e suas representações.

A lei que possibilitou a inserção de identificação histórica dos nomes de ruas, praças e monumentos é a n. II.079 ${ }^{25}$, de 4 de dezembro de 200I, promovida pelo vereador Romeu Santini e sancionada à época pela prefeita Izalene Tiene.

Da mesma maneira que ocorreu no tombamento do Museu do Negro, todas as ações cujos instrumentos públicos e ferramentas foram acionados dentro de um recorte étnico-racial criaram debates sobre a questão de "raça", como exemplifica este registro da reunião do Conselho de Defesa do Patrimônio Cultural de Campinas - Condepacc:

COMUNICAÇÕES DOS CONSELHEIROS: A conselheira Regina Márcia Moura Tavares diz que comentou, em reunião do ano passado, sobre a aprovação pela Câmara Municipal de uma lei sobre políticas afirmativas com a homenagem através de instalação em ruas de placas biográficas de personalidades negras que emprestam os nomes a locais históricos de Campinas, Projeto “Ruas de Histórias Negras". [...] acredita que se vai ser feito para um grupo tem que ser feito para todos. Como o Condepacc pode instruir esse assunto? O presidente Claudiney Carrasco explica que o vereador Carlão faz parte do movimento negro e pode apresentar a lei como quiser. Quem quiser pode procurar outro vereador para fazer uma emenda e complementar a já existente ou fazer outra lei. A conselheira Olga von Simson coloca que o vereador Carlão é do Movimento Negro e não vai lutar pela elite branca. O presidente Claudiney Carrasco diz que este é um assunto polêmico, é um assunto a ser discutido na Câmara ${ }^{26}$.

Cabe registrar que aqui se evidenciam duas problemáticas. A primeira sobre a democracia racial e o persistente racismo no Brasil, cujo processo histórico desde a colonização resultou em desdobramentos registrados que discutiam a superioridade de raças, a miscigenação e a não existência de diferenças biológicas; são todos da raça humana. Esses debates estão inseridos em períodos e momentos específicos com uma conotação de igualdade, já que qualquer política pública voltada à promoção da

25 CÂMARA Municipal de Campinas. Lei n. II.079, de 4 de dezembro de 200I. Dispõe sobre a identificação histórica dos nomes das ruas, praças e monumentos da cidade. Disponível em: <leismunicipais.com.br/a/sp/c/ campinas/lei-ordinaria/200I/II08/II079/lei-ordinaria-n-ᄑro79-200I-dispoe-sobre-a-identificacao-historicados-nomes-das-ruas-pracas-e-monumentos-da-cidade?q=II.079>. Acesso em: 23 nov. 2017.

26 DIÁRIO Oficial do Município de Campinas. Campinas, I5 de abril de 20I6. Disponível em: <campinas.sp.gov. br/uploads/pdf/69I92IIII.pdf >. Acesso em; 5 abr. 2015. 
igualdade racial é vista com um teor de "incoerência" pela "branquitude", que nunca discute amplamente a existência de seus privilégios e a sistêmica representação em todos os espaços e âmbitos da sociedade.

A segunda problemática se constitui nos índices cotidianos de miséria, analfabetismo, moradia, trabalho, mortalidade juvenil, visibilidade em propagandas, diferença social, entre outros. Nesses temas, a negritude continua a aparecer como menos favorecida ou no topo das ocorrências, como no caso de genocídio da juventude negra, com dados verificáveis pelo Instituto Brasileiro de Geografia e Estatística (IBGE).

A placa da Praça Anita Garibaldi reforçou a questão de representação e visibilidade no espaço público de determinada parte da sociedade em detrimento do reconhecimento e preservação da memória da presença negra no território. A reinserção da placa, em frente à Igreja São Benedito, em junho de 20I3, por ordem da Prefeitura Municipal de Campinas, reforçou a surpresa da Comunidade Jongo Dito Ribeiro em novembro, já que nunca se viu tal referência desde 2004, quando o jongo começou a ser praticado ali.

Especificamente sobre o Projeto Ruas de Histórias Negras, iniciaram-se os emplacamentos em 20I5; até setembro de 2016 foram inseridas I5 unidades. Segundo informações da assessora do vereador Carlão (PT), Edna Lourenço, as indicações de ruas pela população têm crescido, mantendo um vasto arquivo de solicitações.

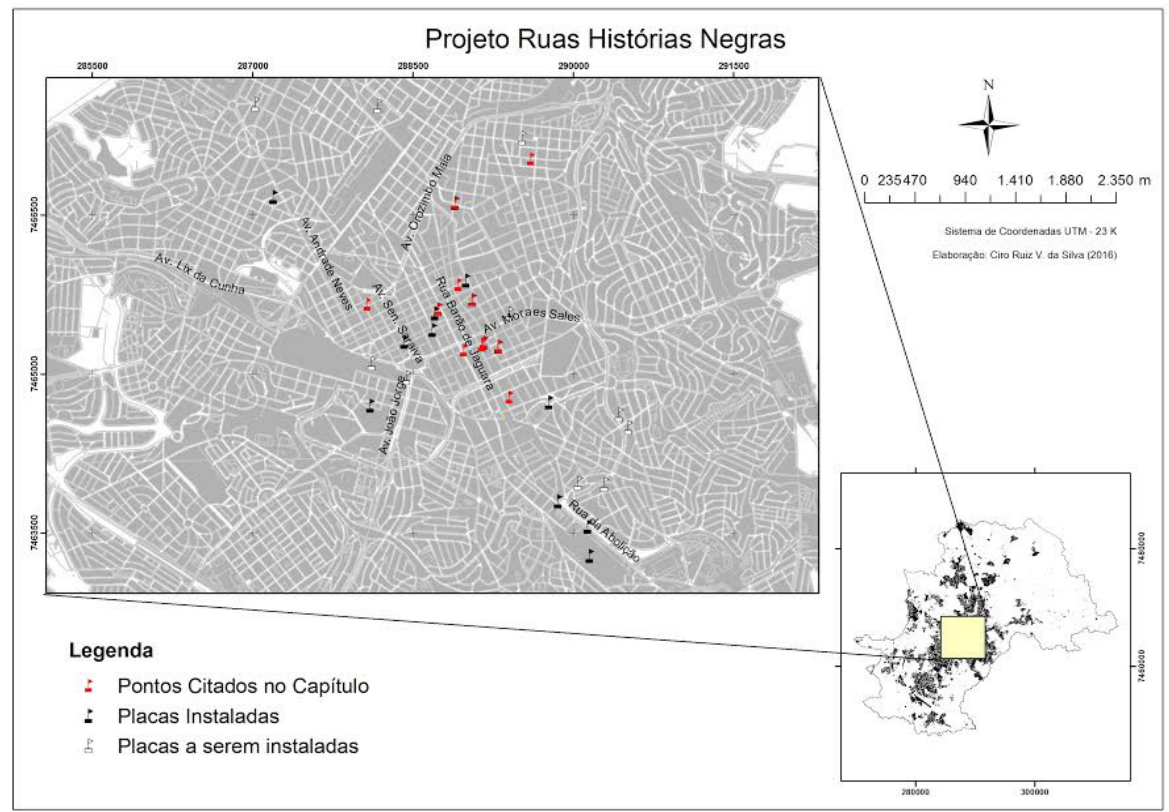

Figura 2 - Mapa com a localização das placas biográficas do Projeto Ruas Negras (instaladas e a serem instaladas)27

27 Fonte: MARTINS, Alessandra Ribeiro, op. cit., p. 283. 
Para a primeira etapa do projeto, foram indicadas 43 localidades já existentes para a inserção das placas biográficas (figuras 3 e 4):

\begin{tabular}{|c|c|c|c|}
\hline Placas & $\begin{array}{l}\text { Nome da rua, alameda } \\
\text { e/ou avenida }\end{array}$ & Ponto de referência & Bairro \\
\hline $\begin{array}{c}\text { Monumento: Estátua da } \\
\text { Mãe Preta }\end{array}$ & Cônego Cipião, 772 & $\begin{array}{l}\text { Em frente à Igreja São } \\
\text { Benedito }\end{array}$ & Centro \\
\hline $\begin{array}{c}\text { Capela: Santa Cruz do } \\
\text { Fundão }\end{array}$ & Abolição, 1.007 & $\begin{array}{c}\text { Capela do Fundão - Nossa } \\
\text { Senhora da Penha }\end{array}$ & Vila Ponte Preta \\
\hline Logradouro: Grande Otelo & Grande Otelo, s/n & $\begin{array}{c}\text { Próximo à Avenida Carlos } \\
\text { Lacerda }\end{array}$ & Vila União \\
\hline Praça: José Neves Baltazar & Quadra 44, s/n & $\begin{array}{l}\text { Entre a Rua Zocca e } \\
\text { Avenida Ibirapuera }\end{array}$ & Vila Castelo Branco \\
\hline Logradouro: Mestre Tito & Mestre Tito & $\begin{array}{l}\text { Próximo ao Teatro Castro } \\
\text { Mendes, esquina com a } \\
\text { Rua Dr. Sales de Oliveira }\end{array}$ & Vila Industrial \\
\hline $\begin{array}{c}\text { Túmulo: } \\
\text { "Escravo"*Toninho }\end{array}$ & $\begin{array}{l}\text { Alameda Central do } \\
\text { Cemitério da Saudade }^{* * *}\end{array}$ & $\begin{array}{c}\text { Ao lado do Túmulo do } \\
\text { Barão Geraldo de Rezende }\end{array}$ & Ponte Preta \\
\hline Logradouro: Luís Gama & Luís Gama, s/n & $\begin{array}{l}\text { Rua Engenheiro Artur } \\
\text { Canguçu paralelo à } \\
\text { Avenida Andrade Neves }\end{array}$ & Botafogo \\
\hline Logradouro: Abolição & Abolição, s/n & $\begin{array}{c}\text { Após o Cemitério da } \\
\text { Saudade }\end{array}$ & Ponte Preta \\
\hline $\begin{array}{l}\text { Avenida: Francisco } \\
\text { Glicério }\end{array}$ & Francisco Glicério & $\begin{array}{c}\text { Próximo ao Largo do } \\
\text { Rosário }\end{array}$ & Centro \\
\hline $\begin{array}{c}\text { Cemitério dos Cativos - } \\
\text { Pretos }\end{array}$ & $\begin{array}{l}\text { Boaventura do Amaral } \\
\text { com Cônego Cipião }\end{array}$ & $\begin{array}{l}\text { Conhecido como Largo } \\
\text { São Benedito, atual Praça } \\
\text { Profa. Silvia Simões } \\
\text { Magro }\end{array}$ & Centro \\
\hline $\begin{array}{l}\text { Logradouro: Laudelina de } \\
\text { Campos Mello }\end{array}$ & $\begin{array}{l}\text { Laudelina de Campos } \\
\text { Mello }\end{array}$ & Conjunto Habitacional & Parque Itajaí \\
\hline $\begin{array}{c}\text { Igreja: Catedral } \\
\text { Metropolitana de } \\
\text { Campinas - Nossa Sra. da } \\
\text { Conceição }\end{array}$ & Praça José Bonifácio, s/n & $\begin{array}{l}\text { Rua Costa Aguiar esquina } \\
\text { com a Rua Treze de Maio }\end{array}$ & Centro \\
\hline Largo: Santa Cruz & Praça XV de novembro & $\begin{array}{c}\text { Ruas Major Solon, Santa } \\
\text { Cruz e Irmãos } \\
\text { Bierremback }\end{array}$ & Cambuí \\
\hline Estádio: Moisés Lucarelli & $\begin{array}{l}\text { Praça Dr. Francisco } \\
\text { Ursaia, } s / n\end{array}$ & Estádio da Ponte Preta & Jardim Proença \\
\hline Largo: das Andorinhas & $\begin{array}{c}\text { Rua Thomaz Alves, } \\
\text { Benjamin Constant e Av. } \\
\text { Anchieta }\end{array}$ & $\begin{array}{l}\text { Antigo Largo do } \\
\text { Pelourinho, em frente ao } \\
\text { atual prédio da Prefeitura } \\
\text { Municipal de Campinas }\end{array}$ & Centro \\
\hline
\end{tabular}

*Encontra-se entre aspas devido aos debates nas discussões étnico-raciais em relação aos termos e conceitos: escravo ou escravizado. O termo "escravo" está associado à imposição do senhor e do processo de escravidão no Brasil. Com a inserção da discussão de Zumbi dos Palmares e lutas do movimento negro, o conceito foi atualizado e tem sido utilizado o termo escravizado desde a década de 1980 nos movimentos sociais negros, dando ênfase ao sentido de imposição, sem condição de escolha. Mas infelizmente, na inserção das placas, essa discussão não foi incorporada nas nomenclaturas; caberia essa atualização terminológica para fortalecimento dos diálogos étnico-raciais e para a discussão nos espaços de educação formal, segundo as diretrizes da Lei 10.639/03. Essa lei propôs novas diretrizes curriculares e tornou obrigatório o ensino da história e cultura afro-brasileira e africana nos ensinos fundamental, médio, particulares e oficiais.

** Para mais informações sobre o Cemitério da Saudade e suas personalidades, ver: PRÓ-MEMÓRIA de Campinas-SP. Monumento: Cemitério da Saudade. Disponível em: <pro-memoria-de-campinas-sp.blogspot.com.br/2007/01/monumento-cemitrio-da-saudade.html>. Acesso em: 27 nov. 2017.

Figura 3 - Placas biográficas de personagens de matriz africana implementadas na primeira etapa 


\begin{tabular}{|c|c|c|c|}
\hline Placas previstas & $\begin{array}{c}\text { Nome da rua e/ou } \\
\text { avenida }\end{array}$ & Ponto de referência & Bairro \\
\hline Praça: Carlos Gomes & Av. Irmã Serafina $\mathrm{s} / \mathrm{n}$ & $\mathrm{Na}$ antiga feira hippie & Centro \\
\hline Largo: do Rosário & $\begin{array}{l}\text { Praça Visconde de } \\
\text { Inadaiatuba }\end{array}$ & Em frente ao Fórum & Centro \\
\hline $\begin{array}{c}\text { Logradouro: Zumbi dos } \\
\text { Palmares }\end{array}$ & $\begin{array}{l}\text { Zumbi dos Palmares, } \\
\mathrm{s} / \mathrm{n}\end{array}$ & $\begin{array}{l}\text { Região do Campo } \\
\text { Grande }\end{array}$ & $\begin{array}{l}\text { Jardim Nova } \\
\text { Esperança }\end{array}$ \\
\hline Avenida 20 de Novembro & $\begin{array}{c}\text { Avenida } 20 \text { de } \\
\text { Novembro }\end{array}$ & $\begin{array}{l}\text { Em frente à Estação } \\
\text { Cultura de Campinas }\end{array}$ & \\
\hline Logradouro: Chica da Silva & Chica da Silva & $\begin{array}{c}\text { Conjunto Hab. Santo } \\
\text { Dias Silva }\end{array}$ & DIC VI \\
\hline Casa da Tulha & $\begin{array}{l}\text { Dr. Alindo Joaquim } \\
\text { de Lemos, } 1316\end{array}$ & $\begin{array}{l}\text { Prédio tombado, que } \\
\text { preserva telhas feitas } \\
\text { nas coxas das escravas }\end{array}$ & Vila Lemos \\
\hline $\begin{array}{c}\text { Logradouro: João da Cruz e } \\
\text { Souza }\end{array}$ & João da Cruz e Souza & 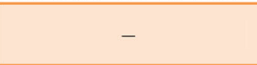 & Jardim Chapadão \\
\hline Praça: José do Patrocínio & - & - & Jardim Brasil \\
\hline $\begin{array}{c}\text { Logradouro: João Cândido } \\
\text { Felisberto (Revolta da } \\
\text { Chibata) }\end{array}$ & $\begin{array}{l}\text { João Cândido } \\
\text { Felisberto }\end{array}$ & $\begin{array}{l}\text { Conj. Hab. Chico } \\
\text { Mendes }\end{array}$ & DIC V \\
\hline Logradouro: Donga & Donga & $\begin{array}{c}\text { Conjunto Hab. Chico } \\
\text { Mendes }\end{array}$ & DIC V \\
\hline $\begin{array}{l}\text { Logradouro: Clementina de } \\
\text { Jesus }\end{array}$ & Clementina de Jesus & $\begin{array}{l}\text { Conj. Hab. Chico } \\
\text { Mendes }\end{array}$ & DIC V \\
\hline Logradouro: Carlos Cachaça & Carlos Cachaça & $\begin{array}{c}\text { Conjunto Hab. Chico } \\
\text { Mendes }\end{array}$ & DIC V \\
\hline $\begin{array}{c}\text { Praça: Angenor Oliveira } \\
\text { Cartola }\end{array}$ & $\begin{array}{l}\text { Praça Angenor } \\
\text { Oliveira Cartola }\end{array}$ & 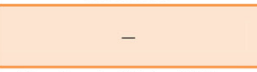 & Vila Lemos \\
\hline Logradouro: Solano Trindade & Solano Trindade & $\begin{array}{c}\text { Conjunto Hab. Chico } \\
\text { Mendes }\end{array}$ & DIC V \\
\hline Logradouro: Ataulfo Alves & Ataulfo Alves & - & Vila Castelo Branco \\
\hline $\begin{array}{l}\text { Logradouro: José Bispo } \\
\text { Clementino dos Santos }\end{array}$ & $\begin{array}{c}\text { José Bispo } \\
\text { Clementino dos } \\
\text { Santos }\end{array}$ & $\begin{array}{c}\text { Conjunto Hab. Lech } \\
\text { Walesa }\end{array}$ & DIC IV \\
\hline Logradouro: Jamelão & Jamelão & $\begin{array}{l}\text { Com. Hab. Lech } \\
\text { Walesa }\end{array}$ & DIC IV \\
\hline Logradouro: Malcom X & Malcom X & $\begin{array}{c}\text { Conjunto Hab. Chico } \\
\text { Mendes }\end{array}$ & DIC V \\
\hline $\begin{array}{c}\text { Instituto: Cultural Babá } \\
\text { Toloji Memória e Identidade } \\
\text { Afro }\end{array}$ & Mário Bassani, 154 & 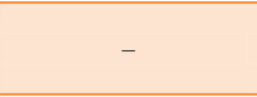 & Jardim São Vicente \\
\hline $\begin{array}{c}\text { Fazenda: Solar das } \\
\text { Andorinhas }\end{array}$ & $\begin{array}{l}\text { Ivan de Abreu } \\
\text { Azevedo, } 333\end{array}$ & - & Bairro Carlos Gomes \\
\hline Logradouro: Papa São Vitor I & Papa São Vitor I & $\begin{array}{c}\text { Conjunto Habitacional } \\
\text { Padre Anchieta }\end{array}$ & Vila Padre Anchieta \\
\hline $\begin{array}{l}\text { Logradouro: Bispo Santo } \\
\text { Agostinho de Hipona }\end{array}$ & $\begin{array}{c}\text { Bispo Santo } \\
\text { Agostinho de Hipona }\end{array}$ & $\begin{array}{c}\text { Conjunto Habitacional } \\
\text { Padre Anchieta }\end{array}$ & Vila Padre Anchieta \\
\hline $\begin{array}{c}\text { Igreja Nossa Senhora } \\
\text { Aparecida }\end{array}$ & $\begin{array}{l}\text { Dr. Joaquim de } \\
\text { Lemos, } 1100\end{array}$ & ( & Jardim Proença \\
\hline Igreja São Benedito & Cônego Cipião, 772 & $\begin{array}{c}\text { Em frente à Estátua da } \\
\text { Mãe Preta }\end{array}$ & Centro \\
\hline Logradouro: Lino Guedes & Lino Guedes & - & Jardim Paulistano \\
\hline $\begin{array}{c}\text { Logradouro: Antônio } \\
\text { Cezarino }\end{array}$ & Antônio Cezarino & - & Cambuí \\
\hline $\begin{array}{c}\text { Logradouro: Benedito } \\
\text { Florêncio }\end{array}$ & Benedito Florêncio & - & Jardim Campinas \\
\hline $\begin{array}{l}\text { Logradouro: Professor } \\
\text { Francisco José de Oliveira }\end{array}$ & $\begin{array}{c}\text { Professor Francisco } \\
\text { José de Oliveira }\end{array}$ & - & Cambuí \\
\hline
\end{tabular}

Figura 4-Localidades indicadas para implementação de placas biográficas 
O levantamento das localidades com nomes de ruas vinculados a personagens de matriz africana possibilitou a percepção de várias questões, como as localidades de cada placa, os bairros em que estão inseridas e as relações desses bairros com a população desses lugares, a historicidade e a escolha de cada um desses pontos. Aparentemente, o critério escolhido para defini-los foi serem parte do ideário "personagens negros", nem todos de Campinas ou com vínculos na cidade - fator que de nenhuma maneira diminui a importância do projeto implementado.

Com esse mapeamento, tornou-se evidente que a ideia de representação de personagens negros está associada também à localização, aos personagens mais populares e fáceis de serem identificados, alguns restritos à periferia de extrema vulnerabilidade na cidade. Decorre daí um estímulo para os moradores, que podem, a partir de suas ruas, reconhecer-se como parte da memória cultural, social e de contribuição para a construção da diversidade brasileira. A rua é um direito de todos, como a cidade, e ocupar esses espaços é possível. No entanto, de outra perspectiva, reforça-se que os lugares da cidade estão predefinidos e, como a seleção se deu em bairros de baixa renda e distantes das áreas centrais, reforça-se também a definição e a quem de destina cada lugar dessa mesma cidade.

\title{
SOBRE OS AUTORES
}

\begin{abstract}
ALESSANDRA RIBEIRO MARTINS é doutora no Programa de Pós-Graduação em Urbanismo da Pontifícia Universidade Católica de Campinas (PUCCampinas), gestora da Casa de Cultura Afro Fazenda Roseira e mestre e liderança da Comunidade Jongo Dito Ribeiro (Campinas/SP).

E-mail: alejongo@gmail.com
\end{abstract}

WILSON RIBEIRO DOS SANTOS JUNIOR é professor titular do Programa de Pós-Graduação em Urbanismo e líder do Grupo de Pesquisa Requalificação Urbana do Centro de Ciências Exatas, Ambientais e de Tecnologia da Pontifícia Universidade Católica de Campinas (Ceatec/PUC-Campinas).

E-mail:wilson@puc-campinas.edu.br

\section{REFERÊNCIAS BIBLIOGRÁFICAS}

BERGÓ, Maria Estela de Abreu. Estudo geográfico da cidade de Campinas. In: CONGRESSO BRASILEIRO DE GEOGRAFIA, X. Anais..., I952. V. III. 
BIKO, Steve. Eu escrevo o que eu quero. São Paulo: Ática, I990.

CÂMARA Municipal de Campinas. Lei n. II.079, de 4 de dezembro de 200I. Dispõe sobre a identificação histórica dos nomes das ruas, praças e monumentos da cidade. Disponível em: <leismunicipais. com.br/a/sp/c/campinas/lei-ordinaria/200I/II08/II079/lei-ordinaria-n-II079-200I-dispoe-sobre-a -identificacao-historica-dos-nomes-das-ruas-pracas-e-monumentos-da-cidade?q=II.079>. Acesso em: 23 nov. 2017.

DIÁRIO Oficial do Município de Campinas. Campinas, I5 de abril de 20I6. Disponível em: <campinas. sp.gov.br/uploads/pdf/69I92IIII.pdf >. Acesso em: 5 abr. 2015.

FRANKLIN, John Hope. Raça e história - ensaios selecionados (I938-I988). Tradução de Mauro Gama. Rio de Janeiro: Rocco, I999.

GOULART, Edmo. Campinas: ruas da época imperial. Campinas: Maranata, I983.

HAESBAERT, R. Territórios alternativos. Niterói: Eduff; São Paulo: Contexto, 2002.

HOBSBAWN, Eric. Sobre história. São Paulo: Companhia das Letras, I998.

MARIANO, Julio. Campinas de ontem e anteontem. Campinas: Maranata, I970.

MARTINS, Alessandra Ribeiro. Requalificação urbana: a Fazenda Roseira e a Comunidade Jongo Dito Ribeiro - Campinas/SP. Dissertação (Mestrado em Urbanismo). Programa de Pós-Graduação em Urbanismo, Pontifícia Universidade Católica de Campinas, 20Ir. Disponível em: <tede.bibliotecadigital. puc-campinas.edu.br:8080/jspui/handle/tede/97>. Acesso em: 23 nov. 2017.

. Matriz africana em Campinas - territórios, memória e representação. Tese (Doutorado em Urbanismo). Programa de Pós-Graduação em Urbanismo, Pontifícia Universidade Católica de Campinas, 20I6. Disponível em: <tede.bibliotecadigital.puc-campinas.edu.br:8080/jspui/handle/tede/928>. Acesso em: 23 nov. 20I7.

PESAVENTO, Sandra Jatahy. Cidade, espaço e tempo: reflexões sobre a memória e o patrimônio urbano. Cadernos do Lepaarq, v. 2, n. 4, ago.-dez. 2005, p. 9-I7.

PREFEITURA Municipal de Campinas. Câmara Municipal de Campinas. Arq-Camp. Base de dados de referências de acervos arquivísticos públicos de Campinas. Código de Posturas de I872. Disponível em: <arq-camp.campinas.sp.gov.br/index.php/pI7?symfony=3eqjsoIfv5d4Itcahv2tckdqr3〉. Acesso em: 23 nov. 2017.

PRÓ-MEMÓRIA de Campinas-SP. Monumento: Cemitério da Saudade. Disponível em: <pro-memoriade-campinas-sp.blogspot.com.br/2007/oI/monumento-cemitrio-da-saudade.html〉. Acesso em: 27 nov. 2017.

RIBEIRO, Matilde. Políticas de promoção da igualdade racial no Brasil - I986-20Io. Rio de Janeiro: Garamond, 20I4.

RODRIGUES, Fabíola. Perfil populacional de Campinas: a contribuição das migrações. In: PESSOA, Ângelo E. S. (Org. e Coord.). Conhecer Campinas numa perspectiva histórica. Campinas: Secretaria Municipal de Educação, 2004.

ROLNIK, Raquel. A cidade e a lei: legislação, política urbana e territórios na cidade de São Paulo. São Paulo: Fapesp/Studio Nobel, I977.

THOMPSON, Edward Paul. A miséria da teoria. Rio de Janeiro: Jorge Zahar, I98I.

VILELLA, Américo Baptista. Representações da cidade: patrimônio cultural imaterial e memória republicana em Campinas. Revista CPC, São Paulo, n. 6, p. IO2-II8, maio-out. 2008. Disponível em: <periodicos. usp.br/cpc/article/view/I5626/I7200>. Acesso em: 23 nov. 2017. 